Supplement of Geosci. Model Dev., 11, 2299-2314, 2018

https://doi.org/10.5194/gmd-11-2299-2018-supplement

C Author(s) 2018. This work is distributed under

the Creative Commons Attribution 4.0 License.

(c) (1)

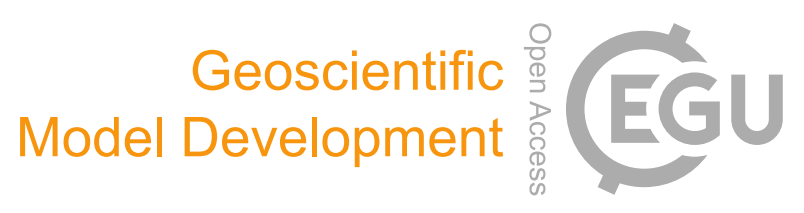

Supplement of

\title{
A new approach for simulating the paleo-evolution of the Northern Hemisphere ice sheets
}

\author{
R. Banderas et al. \\ Correspondence to: Rubén Banderas (banderas.ruben@ fis.ucm.es)
}

The copyright of individual parts of the supplement might differ from the CC BY 4.0 License. 

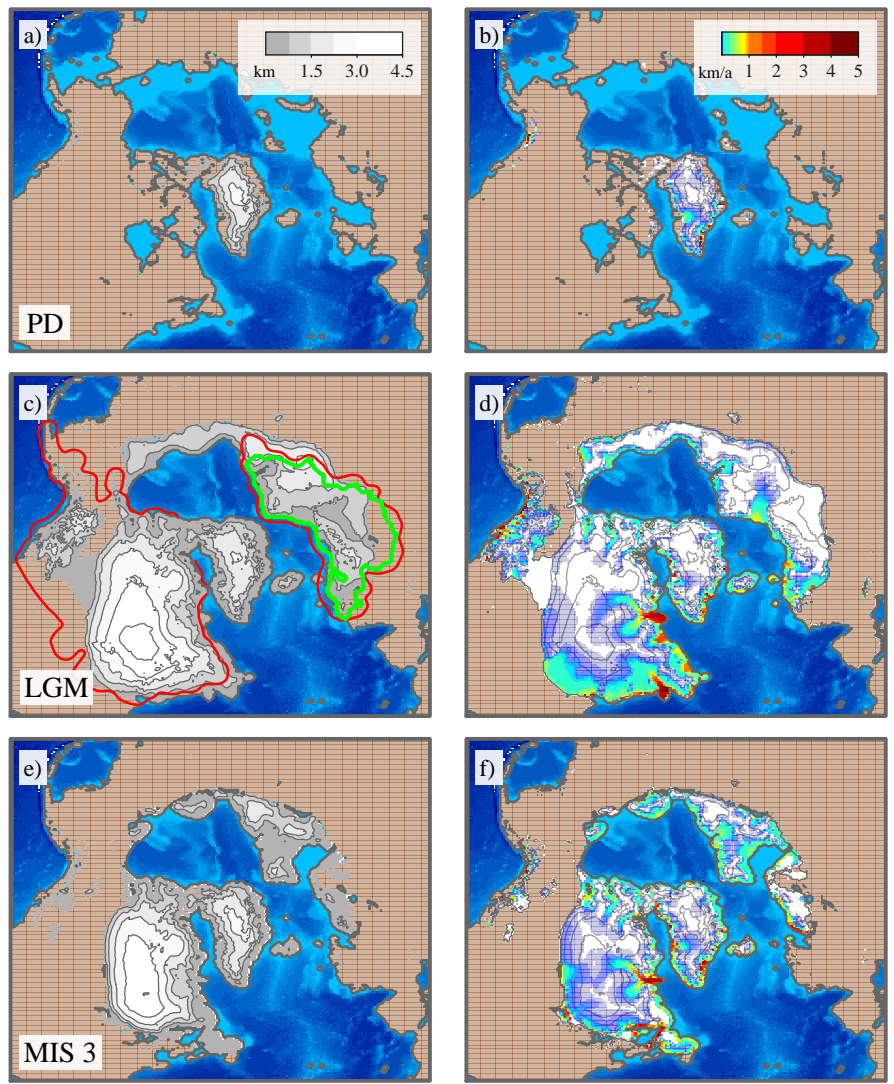

Figure 1. NH ice-sheet configurations at different stages of the last glacial-interglacial period as simulated under the M1 method in which the temporal evolution of temperature and precipitation is calculated by means of a unique index that modulates the contribution of the glacial-interglacial spatial anomaly: a) present-day ice thickness ( $\mathrm{km}$ ) and b) present-day ice velocities $\left(\mathrm{km} \mathrm{a}^{-1}\right)$. Panels c)-d) and e)-f) show the same information as a)-b) for the LGM and MIS3 stages, respectively. Red and green contours in panel c) represent the ICE-5G (Peltier, 2004) and DATED-1 (Hughes et al., 2016) extent of NH ice sheets at the LGM, respectively . 

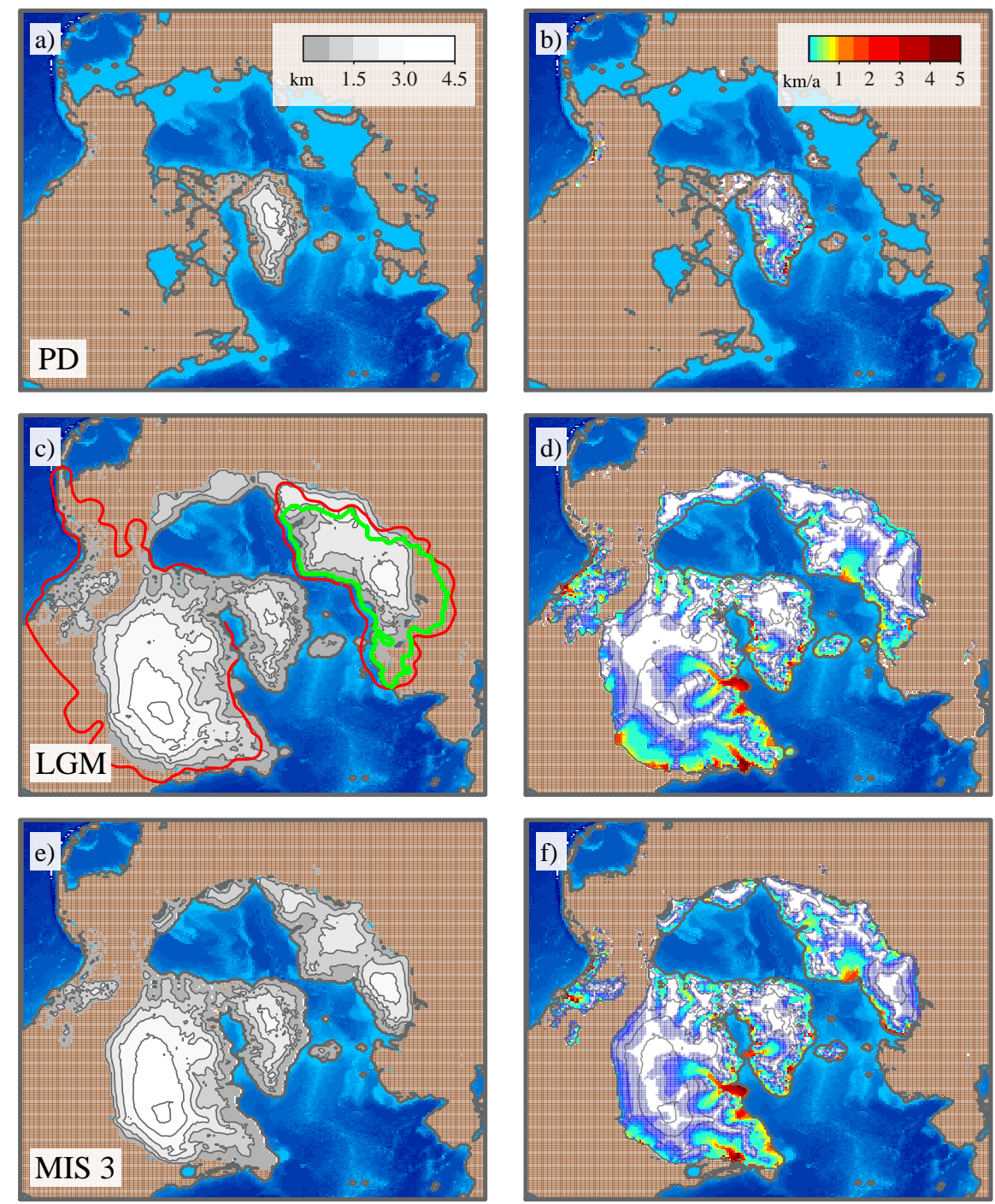

Figure 2. NH ice-sheet configurations at different stages of the last glacial-interglacial period as simulated under the M2 method in which the temporal evolution of temperature and precipitacion is calculated by means of two indices that separately modulate the contribution of the glacial-interglacial and stadial-interstadial spatial anomalies: a) present-day ice thickness $(\mathrm{km})$ and b) present-day ice velocities $\left(\mathrm{km}^{-1}\right)$. Panels ()-d) and e)-f) show the same information as a)-b) for the LGM and MIS3 stages, respectively. Red and green contours in panel c) represent the ICE-5G (Peltier, 2004) and DATED-1 (Hughes et al., 2016) extent of NH ice sheets at the LGM, respectively. 


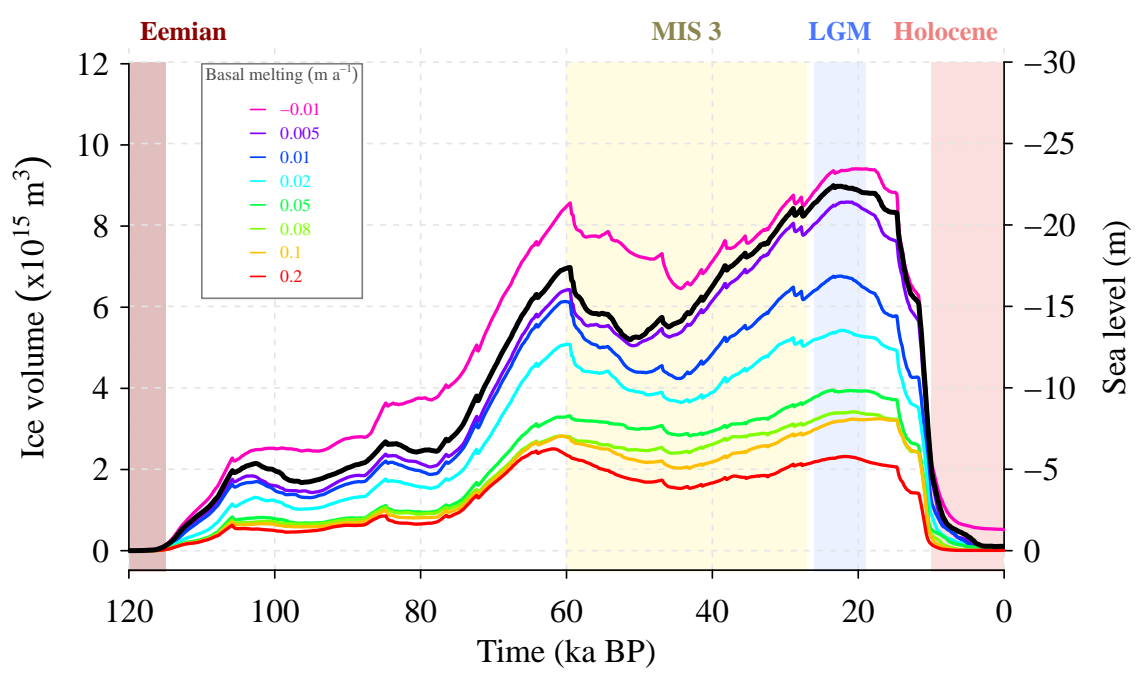

Figure 3. Response of the FIS to different values of oceanic basal melting $\left(\mathrm{m} \mathrm{a}^{-1}\right)$. Variations of basal melting values are only considered in shallow oceanic regions. Black solid line represents the evolution of ice volume $\left(\mathrm{m}^{3}\right)$ for an oceanic basal melting value fixed to $0 \mathrm{~m} \mathrm{a}^{-1}$. Ice volume variations have also been expressed in SLE units (m). 


\section{References}

Hughes, A. L., Gyllencreutz, R., Lohne, Ø. S., Mangerud, J., and Svendsen, J. I.: The last Eurasian ice sheets-a chronological database and time-slice reconstruction, DATED-1, Boreas, 45, 1-45, 2016.

Peltier, W.: Global glacial isostasy and the surface of the ice-age Earth- The ICE-5 G(VM 2) model and GRACE, Ann. Rev. Earth and Plan. Sci., 32, 111-149, https://doi.org/10.1146/annurev.earth.32.082503.144359, 2004. 